\title{
U⿱宀⿻三丨口
}

\section{Simulation of thermal hazards from hydrogen under-expanded jet fire}

Cirrone, D. M. C., Makarov, DV., \& Molkov, V. (2019). Simulation of thermal hazards from hydrogen underexpanded jet fire. International Journal of Hydrogen Energy, 44(17), 8886-8892.

https://doi.org/10.1016/j.ijhydene.2018.08.106

Link to publication record in Ulster University Research Portal

\section{Published in:}

International Journal of Hydrogen Energy

Publication Status:

Published (in print/issue): 02/04/2019

DOI:

10.1016/j.ijhydene.2018.08.106

\section{Document Version}

Author Accepted version

\section{General rights}

Copyright for the publications made accessible via Ulster University's Research Portal is retained by the author(s) and / or other copyright owners and it is a condition of accessing these publications that users recognise and abide by the legal requirements associated with these rights.

\section{Take down policy}

The Research Portal is Ulster University's institutional repository that provides access to Ulster's research outputs. Every effort has been made to ensure that content in the Research Portal does not infringe any person's rights, or applicable UK laws. If you discover content in the Research Portal that you believe breaches copyright or violates any law, please contact pure-support@ulster.ac.uk. 


\title{
SIMULATION OF THERMAL HAZARDS FROM HYDROGEN UNDER- EXPANDED JET FIRE
}

\author{
Cirrone, D.M.C., Makarov, D. and Molkov, V. \\ ${ }^{1}$ Hydrogen Safety Engineering and Research Centre (HySAFER), \\ Ulster University, Shore Road, Newtownabbey, BT37 0QB, UK, \\ cirrone-dmc@ulster.ac.uk, dv.makarov@ulster.ac.uk, v.molkov@ulster.ac.uk
}

\begin{abstract}
Thermal hazards from an under-expanded (900 bar) hydrogen jet fire have been numerically investigated. The simulation results have been compared with the flame length and radiative heat flux measured for the horizontal jet fire experiment conducted at INERIS. The release blowdown characteristics have been modelled using the volumetric source as an expanded implementation of the notional nozzle concept. The CFD study employs the realizable $\kappa-\varepsilon$ model for turbulence and the Eddy Dissipation Concept for combustion. Radiation has been taken into account through the Discrete Ordinates (DO) model. The results demonstrated good agreement with the experimental flame length. Performance of the model shall be improved to reproduce the radiative properties dynamics during the first stage of the release (time $<10 \mathrm{~s}$ ), whereas, during the remaining blowdown time, the simulated radiative heat flux at five sensors followed the trend observed in the experiment.
\end{abstract}

Keywords: CFD, jet fire, high pressure, hydrogen safety, radiative heat transfer, under-expanded jet

\section{INTRODUCTION}

The main currently considered technology for onboard hydrogen storage in automotive applications is the high-pressure gas compression (350-700 bar). In the case of release from a damaged pressurised storage system or Thermal Pressure Relief Device (TPRD) opening, hydrogen is likely to ignite producing a jet fire. The consequent flame length can cover distances of tens of meters and cause lifethreatening conditions by the flame itself and thermal radiation. Predictive tools shall be developed to be used in hydrogen safety engineering to assure safer deployment of hydrogen technology and related infrastructure. Computational Fluid Dynamics (CFD) proved to be a practical predictive tool for modelling realistic accident scenarios and quantifying the related hazards. Several numerical studies have been conducted on modelling and simulation of high pressure hydrogen jet flames targeting to reproduce the flame length and width, such as [1]-[3]. However, fewer studies have analysed the emitted thermal radiation to validate radiation simulations against experiments [4]. The present study is aimed to simulate dynamics of the radiative heat transfer and flame length of a hydrogen jet fire resulting from the high-pressure tank blowdown.

\section{DESCRIPTION OF THE EXPERIMENT}

The CFD study is aimed to simulate the horizontal jet fire experiment conducted at INERIS in France [5]. The experimental facility is shown in Figure 1. The release system was arranged in an $80 \mathrm{~m}$ long gallery with cross section dimensions $3 \times 4 \mathrm{~m}$. The gallery was open at one end and a chimney with square cross section was located at the opposite blind extremis[6]. Hydrogen was released from a 251 tank with initial pressure 930 bar. The release nozzle was located on the centre-line of the gallery and $1.5 \mathrm{~m}$ above the ground, the nozzle orifice diameter was $2 \mathrm{~mm}$. A fire proof wall approximately $1.7 \mathrm{~m}$ tall and $1.2 \mathrm{~m}$ wide was located behind the release nozzle to protect the hydrogen tank. A niche with dimensions $4 \times 4 \times 4$ $\mathrm{m}$ was present in proximity of the release [7]. Figure 2 shows the detail of the recess area and locations of five sensors measuring the radiative heat flux from the flame. The radiometers were located on a line forming a $45^{\circ}$ angle with jet axis. The flame length was measured through a video camera positioned at $5 \mathrm{~m}$ distance from the flame. The tank temperature and pressure were recorded during the entire release duration. 


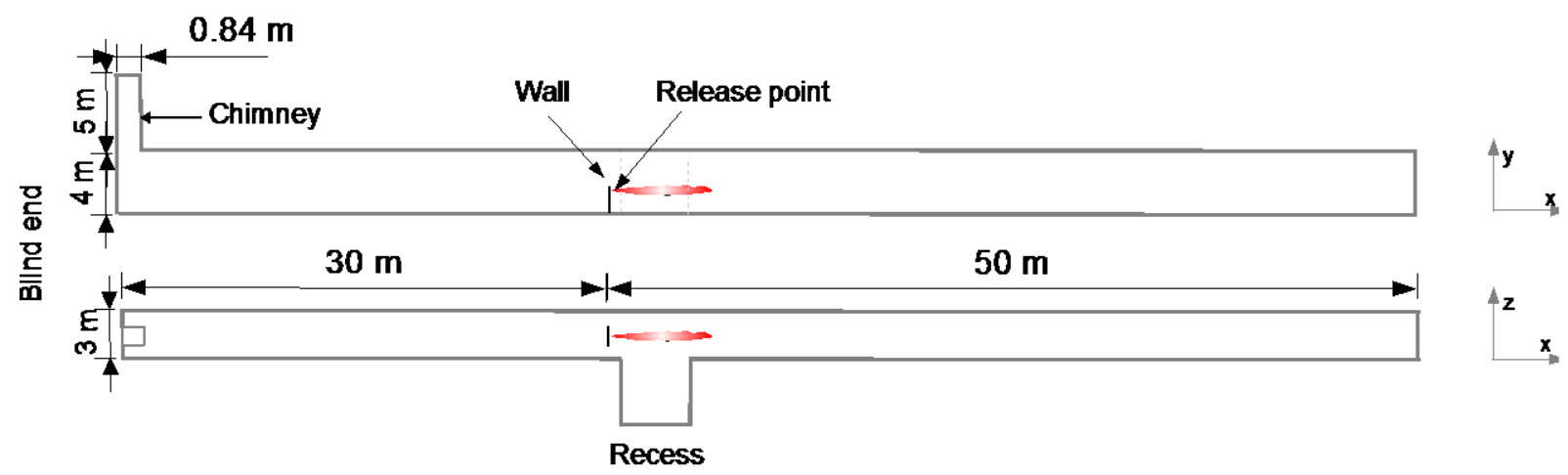

Figure 1. General view (top) and plan view (bottom) of the experimental facility

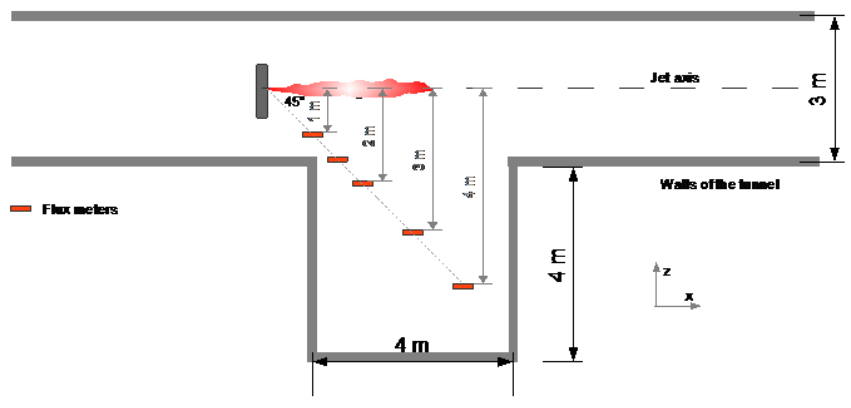

Figure 2. Detail of recess area and sensors position

\section{NUMERICAL MODEL}

\subsection{Governing equations}

The model is based on the Reynolds-Averaged Navier-Stokes (RANS) conservation equations for mass, momentum, energy and species:

$$
\begin{aligned}
& \frac{\partial \rho}{\partial t}+\frac{\partial\left(\rho u_{i}\right)}{\partial x_{i}}=0 \\
& \frac{\partial\left(\rho u_{i}\right)}{\partial t}+\frac{\partial\left(\rho u_{i} u_{j}\right)}{\partial x_{i}}=-\frac{\partial p}{\partial x_{i}}+\frac{\partial}{\partial x_{i}}\left(\mu+\mu_{t}\right)\left(\frac{\partial u_{i}}{\partial x_{j}}+\frac{\partial u_{j}}{\partial x_{i}}-\frac{2}{3} \frac{\partial u_{k}}{\partial x_{k}} \delta_{i j}\right)+\rho g_{i} \\
& \frac{\partial(\rho E)}{\partial t}+\frac{\partial}{\partial x_{i}}\left(u_{i}(\rho E+p)\right) \\
& =\frac{\partial}{\partial x_{i}}\left[\left(k_{t}+\frac{\mu_{t} c_{p}}{P r_{t}}\right) \frac{\partial T}{\partial x_{i}}-\sum_{m} h_{m}\left(-\left(\rho D_{m}+\frac{\mu_{t}}{S c_{t}}\right) \frac{\partial Y_{m}}{\partial x_{i}}\right)+u_{i}\left(\mu+\mu_{t}\right)\left(\frac{\partial u_{i}}{\partial x_{j}}+\frac{\partial u_{j}}{\partial x_{i}}-\frac{2}{3} \frac{\partial u_{k}}{\partial x_{k}} \delta_{i j}\right)\right]+S_{E} \\
& \frac{\partial \rho Y_{m}}{\partial t}+\frac{\partial}{\partial x_{i}}\left(\rho u_{i} Y_{m}\right)=\frac{\partial}{\partial x_{i}}\left[\left(\rho D_{m}+\frac{\mu_{t}}{S c_{t}}\right) \frac{\partial Y_{m}}{\partial x_{i}}\right]+S_{m}
\end{aligned}
$$


where $\rho$ is the density, $t$ is the time, $u$ corresponds to velocity components in $i, j$ and $k$ Cartesian directions, $p$ is the pressure, $\mu_{t}$ is the turbulent dynamic viscosity, $\delta_{i j}$ is the Kronecker symbol, $g_{i}$ is the gravity acceleration in $i$-axis direction, $E$ is the total energy, $k_{t}$ is the thermal conductivity, $c_{p}$ is the specific heat at constant pressure, $P r_{t}$ and $S c_{t}$ are the turbulent Prandtl and Schmidt numbers equal to 0.85 and 0.7 respectively, $m$ is the chemical species with mass fraction $Y_{m}$ and molecular diffusivity $D_{m}, S_{E}$ and $S_{m}$ are the source terms for energy and chemical species.

Realizable $k-\varepsilon$ model [8] is used for turbulence modelling because of its better capability to predict the spreading rate of axisymmetric jets [9]. The model solves the transport equations for turbulence kinetic energy, $k$, and turbulent dissipation rate, $\varepsilon$, as follow:

$$
\begin{aligned}
& \frac{\partial(\rho k)}{\partial t}+\frac{\partial\left(\rho k u_{i}\right)}{\partial x_{i}}=\frac{\partial}{\partial x_{i}}\left[\left(\mu+\frac{\mu_{t}}{\sigma_{k}}\right) \frac{\partial k}{\partial x_{i}}\right]+G_{k}+G_{b}-\rho \varepsilon-Y_{M}, \\
& \frac{\partial(\rho \varepsilon)}{\partial t}+\frac{\partial\left(\rho \varepsilon u_{i}\right)}{\partial x_{i}}=\frac{\partial}{\partial x_{i}}\left[\left(\mu+\frac{\mu_{t}}{\sigma_{\varepsilon}}\right) \frac{\partial \varepsilon}{\partial x_{i}}\right]+\rho C_{1} S \varepsilon-\rho C_{2} \frac{\varepsilon^{2}}{k+\sqrt{v \varepsilon}}+C_{1 \varepsilon} \frac{\varepsilon}{k} C_{3 \varepsilon} G_{b} .
\end{aligned}
$$

where $G_{k}$ and $G_{b}$ correspond to the generation of $k$ by, respectively, mean velocity gradients and buoyancy, $Y_{M}$ represents the contribution of the fluctuating dilatation in compressible turbulence to the overall dissipation rate, $\sigma_{k}$ and $\sigma_{\varepsilon}$ are the turbulent Prandtl numbers for $k$ and $\varepsilon$ equal to 1 and 1.2 respectively, $v$ is the kinematic viscosity. $C_{1}$ is evaluated as a function of the modulus of the mean rate of strain tensor, $S . C_{2}$ and $C_{1 \varepsilon}$ are constants equal to 1.9 and 1.44 , while $C_{3 \varepsilon}$ is function of the flow velocity components with respect to the gravitational vector.

Combustion is modelled through the Eddy Dissipation Concept model [10]. The rate of reaction of the species $i$ is evaluated as follow:

$$
R_{i}=\frac{\rho\left(\xi^{*}\right)^{2}}{\tau^{*}\left[1-\left(\xi^{*}\right)^{3}\right]}\left(Y_{i}^{*}-Y_{i}\right)
$$

with $\xi^{*}=C_{\xi}\left(\frac{v \varepsilon}{k^{2}}\right)^{1 / 4}$ and $\tau^{*}=C_{\tau}\left(\frac{v}{\varepsilon}\right)^{1 / 2}$,

where $Y_{i}$ is the species mass fraction, $Y_{i}^{*}$ is the fine scale species mass fraction after reacting over the time $\tau^{*}, \xi^{*}$ is the fine scale length. $C_{\xi}$ and $C_{\tau}$ are the volume fraction and time scale constants, equal to 2.1377 and 0.4082. Detailed chemical mechanism is incorporated in the EDC model and here the authors used the same model as in [11], which considers a subset of Peters and Rogg's kinetic mechanism [12] with 18-step reduced chemical reaction mechanism for hydrogen combustion in air.

The Discrete Ordinates model is employed for radiation [13]. The Radiative Transfer Equation (RTE) evaluates the radiation intensity, $I$, for a finite number of solid angles $\Omega^{\prime}$ associated to the direction $\vec{s}$ :

$$
\nabla(I(\vec{r}, \vec{s}) \vec{s})+\left(\kappa+\sigma_{s}\right) I(\vec{r}, \vec{s})=\kappa n^{2} \frac{\sigma T^{4}}{\pi}+\frac{\sigma_{s}}{4 \pi} \int_{0}^{4 \pi} \mathrm{I}\left(\vec{r}, \vec{s}^{\prime}\right) \Phi\left(\vec{s} \cdot \vec{s}^{\prime}\right) d \Omega^{\prime}
$$

where the coefficient $\kappa$ is the absorption coefficient, $\sigma_{\mathrm{s}}$ is the scattering coefficient, $\vec{r}$ is the position vector in $\vec{s}$ direction, $n$ is the refractive index and $\Phi$ is the scattering phase function. 


\subsection{Blowdown dynamics}

The release from the high-pressure hydrogen storage (930 bar) results in an under-expanded jet. The area where the flow expands to ambient pressure is characterised by the presence of shock waves and supersonic velocities, preventing the use of incompressible codes and requiring highly refined numerical grids. Therefore, the release source was modelled through the Ulster notional nozzle approach [14]. The model is based on mass and energy conservation equations, accounts the non-ideal behavior of hydrogen at extremely high pressure through the Abel-Noble equation of state, and describes the expansion process as isentropic. The flow is characterized by uniform sonic velocity and ambient pressure at the notional nozzle, simplifying significantly the problem by allowing to skip simulation of shock structures and considering the jet flow at the notional nozzle as completely expanded. Complete description of the approach and employed equations are available in [14]. The described above notional nozzle approach was applied to simulate the under-expanded jet properties dynamics during the tank blowdown. A discharge coefficient, $C_{d}$, was considered in calculation of the mass flow rate as follow: $\dot{m}=C_{d} \cdot \rho \cdot u \cdot A$. The discharge coefficient was evaluated through the inverse problem method according to the experimental data on mass flow rate released from the tank, and it resulted to be equal to 0.7 . In a first analysis, the blowdown was treated as adiabatic. However, there is an experimental evidence, see [15], that heat transfer between the storage system and the surroundings can affect the blowdown dynamics: during blowdown process from a 431 tank the stagnation temperature in the tank started to increase after about $140 \mathrm{~s}$. Therefore, a second case was investigated, treating the blowdown as adiabatic in the first phase of the release and as isothermal when temperature decreased to $215 \mathrm{~K}$, to mimic the experimental trend [5]. Comparison of reservoir temperature dynamics for the two limiting simulated cases and experimental observations for tank temperature is shown in Figure 3. Pressure dynamics is shown in Figure 4. The adiabatic calculation seems to be closer to the experimental pressure curve, although the difference between the two simulated cases is negligible. This may be attributed to the not long enough discharge time for the heat transfer to affect the blowdown dynamics. The same observations could be made for the mass flow rate shown as function of overpressure in Figure 5, where it can be seen that the mass flow rate for the adiabatic case is slightly larger than the adiabatic to isothermal case when the overpressure drops to 200 bar (after $12 \mathrm{~s}$ ). The adiabatic to isothermal formulation was chosen to represent the problem under study, as it gave better correspondence to the experimental temperature in the reservoir, which affects, along with pressure, the jet properties evaluated at the real and notional nozzles.

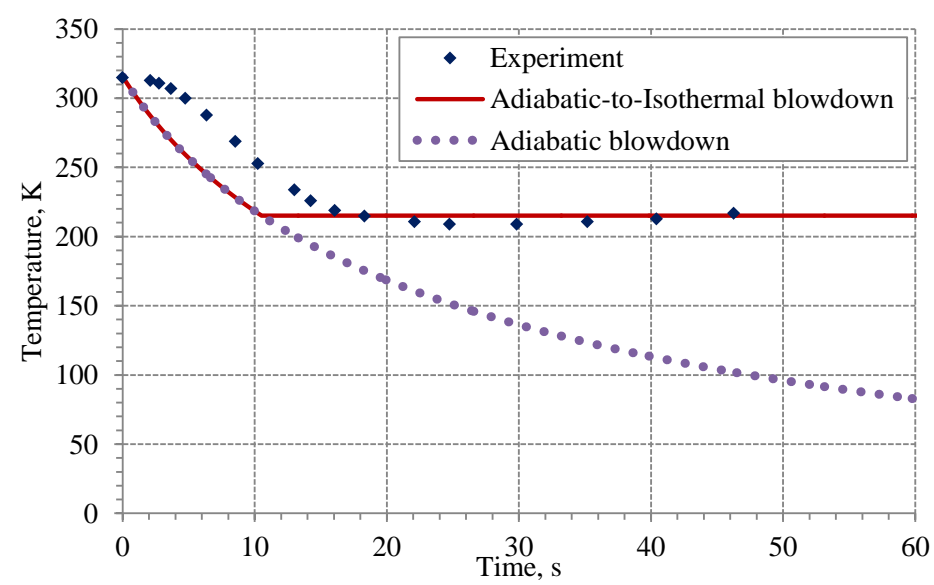

Figure 3. Temperature in the reservoir during tank blowdown 


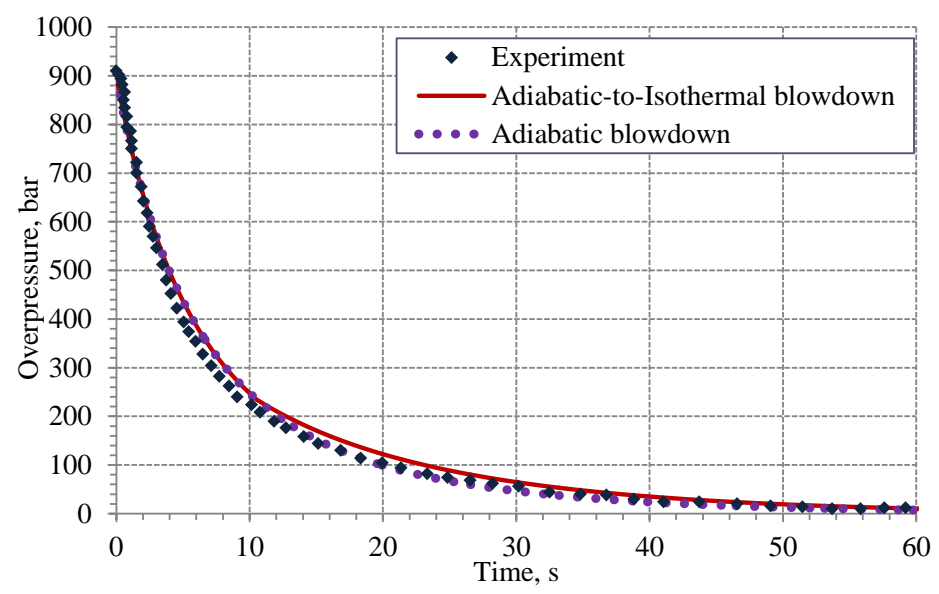

Figure 4. Pressure in the reservoir during tank blowdown

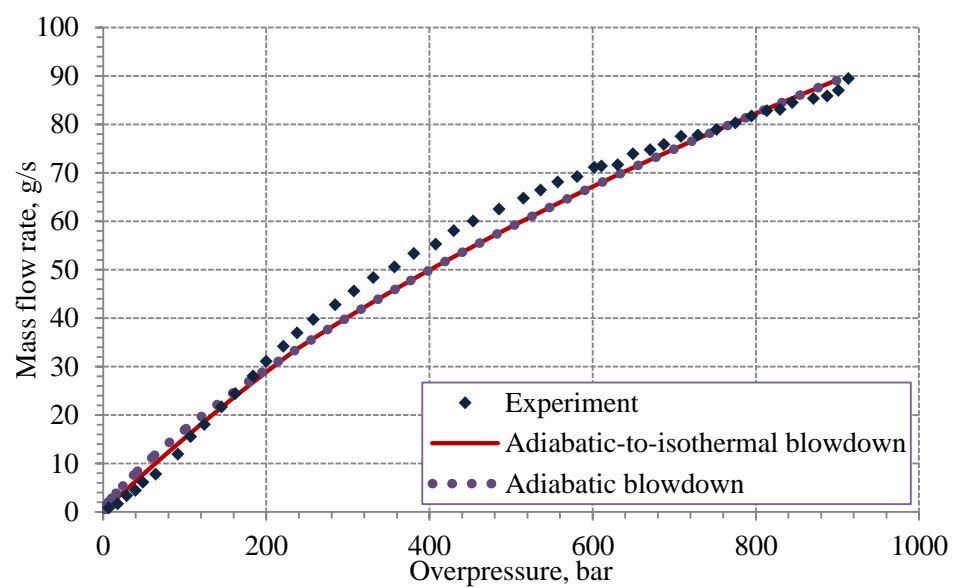

Figure 5. Mass flow rate released during tank blowdown

\subsection{Computational domain and numerical details}

Employing the notional nozzle diameter as inflow boundary with specified flow velocity would require the change of the numerical grid because the release conditions in the notional nozzle and its diameter are changing during blowdown process. To avoid the change of grid, the release of hydrogen was reproduced through the volumetric source implementation of the notional nozzle approach [16]. This approach is based on the evaluation of source terms for mass, momentum, energy, turbulent kinetic energy and turbulent dissipation rate depending on the dynamics of properties at the notional nozzle. Source terms are applied to a constant cylinder volume, thus responsible for the hydrogen release. The equilateral cylinder diameter is $3.1 \mathrm{~cm}$ and it corresponds to the value of the notional nozzle at the beginning of the blowdown. The range of validity of the volumetric source approach is limited to $S i z e_{V S} \leq 4 d_{e f f}$, meaning that at least about $35 \mathrm{~s}$ of release can be simulated without any further modification of the mesh. This limitation to the simulation is accepted, as the most dangerous phase of the release, characterized by longer flame length and radiative heat flux, is contained within this time, and at $35 \mathrm{~s}$, pressure in the tank has already dropped to about 50 bar from initial value 900 bar. Ansys Fluent was employed as CFD software. The calculation domain includes the entire $80 \mathrm{~m}$ gallery. The fire-proof wall dimensions were approximated as $1.2 \times 1.7 \times 0.1 \mathrm{~m}$. The niche was assumed to be located at $1 \mathrm{~m}$ from the release point, as this is the position that better allows the placement of five radiative heat flux sensors. The chimney was assumed to be at the centre of the gallery blind end. The solid ground was meshed to include the evaluation of conjugate heat transfer with the flame. Control volumes size varied from about $2 \mathrm{~mm}$ at the release to $3 \mathrm{~m}$ toward the end of the gallery. Smaller control volume sizes $(0.5 \mathrm{~mm})$ were used in the solid body for the layer of cells of the ground surface, so that it would be 
sufficiently refined to resolve the conduction heat transfer across the body. Expansion ratio between neighboring control volumes was limited to 1.1 in proximity of the release, whereas it was increased to 1.2 in the far field. The total number of control volumes was 1,260,049. The fluid part was constituted by $965,445 \mathrm{CV}$ s while the remaining $\mathrm{CV}$ s formed the solid ground. The minimum orthogonal quality and the skewness of the mesh were 0.49 , in agreement with the minimum numerical requirements defined in [17] for modelling hydrogen release and dispersion. Figure 6a shows the mesh section corresponding to the plane where the release exit is located $(x=0)$. Figure $6 \mathrm{~b}$ shows in detail the release volume, indicated in green, and the short tube separating the release volume and the wall. The gallery walls and ground were considered as non-slip surfaces made of concrete. Density was considered equal to $2300 \mathrm{~kg} / \mathrm{m}^{3}$, specific heat of $900 \mathrm{~J} / \mathrm{kgK}$ and thermal conductivity equal to $1.95 \mathrm{~W} / \mathrm{mK}$ [18]. Emissivity was fixed equal to 0.94 [19]. Kirchhoff's law was applied, thus, emissivity of the surface is equal to the absorptivity of incident radiation. The wall behind the release nozzle was considered to be highly reflective with emissivity equal to 0.09 , as indicated for aluminium foils [19]. The radiometers were modelled as $10 \times 10 \mathrm{~cm}$ surfaces, so that the dimensions would coincide with the numerical grid size in the space where they are located. The sensors were modelled as isothermal non-slip walls with emissivity 1. The isothermal assumption prevents the increase of sensors temperature because of absorbed radiation. Emissivity equal to 1 imposes that the entire received radiation is absorbed and not reflected and that the sensors emit as black bodies. However, temperature of sensors will be equal to that of environment, $288 \mathrm{~K}$, thus, there will be no radiation losses from radiometers to their surroundings, which would affect the net radiation received by the sensors. The chimney opening and the gallery open end were modelled as pressure-outlet with gauge pressure equal to $0 \mathrm{~Pa}$. The ambient conditions were $288 \mathrm{~K}$ and 1 bar. Moist air was considered for the simulation. Water vapour mass fraction was imposed equal to 0.006 ( $1 \%$ by volume), indicated as typical value for atmosphere [20].

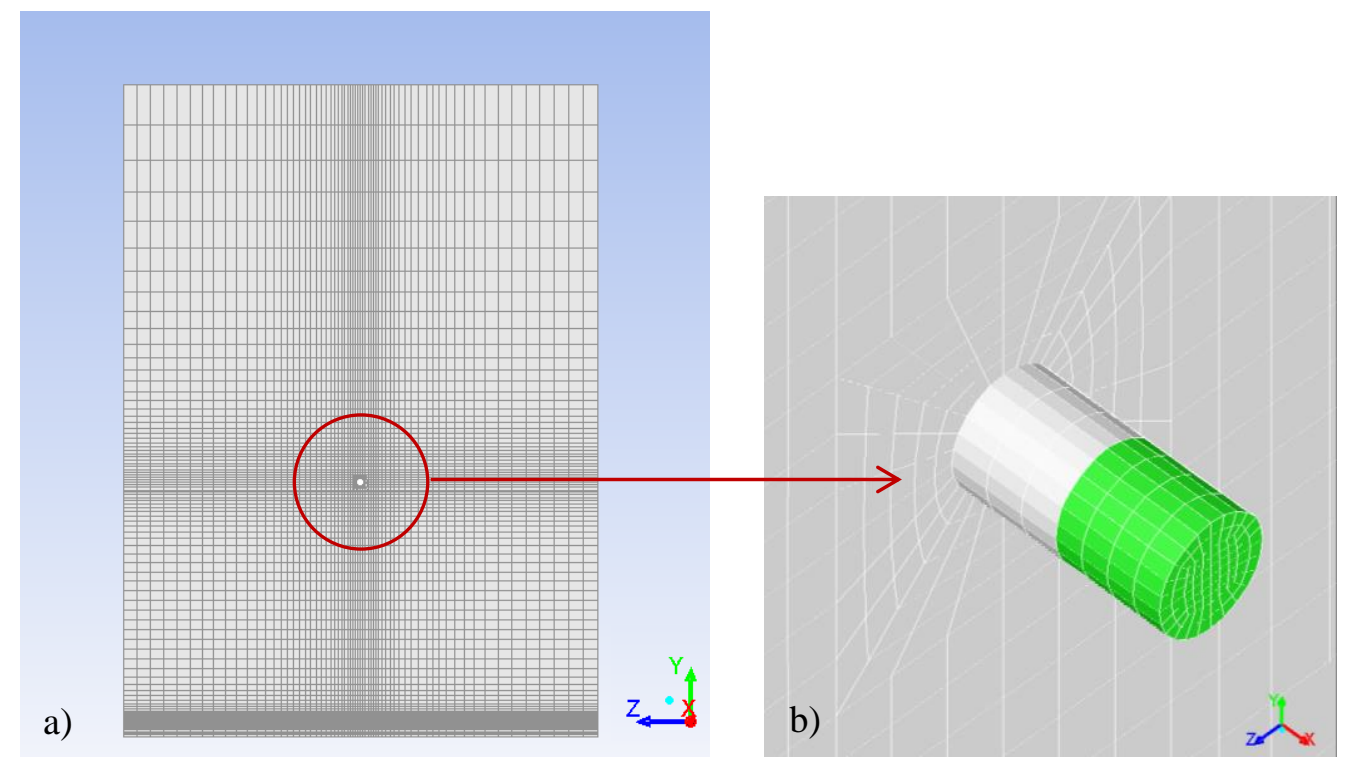

Figure 6. Calculation domain and numerical mesh: a) cross section at $x=0$; b) enlargement of the volumetric source area

Water vapour was considered as a media participating in radiative heat transfer with mean Planck absorption coefficient evaluated as function of temperature and partial pressure according to the data presented in [21]. Scattering was neglected. RTE was discretised employing $5 \times 5$ angular divisions and $3 \times 3$ pixels, as suggested in [22] for problems involving large gradients of temperature in space. Pressurebased solver was employed along with the incompressible gas assumption. SIMPLE procedure was chosen for velocity-pressure coupling, whereas convective terms were discretized using the second order upwind. Time step equal to $10^{-3} \mathrm{~s}$ was applied at the initial stage of simulations (up to about $2 \mathrm{~s}$ ) and it was increased with the simulations advancement in time up to $0.01 \mathrm{~s}$. 


\section{RESULTS AND DISCUSSION}

The received radiative heat flux was monitored at five sensors located at different distances from the flame, as discussed and shown in Section 2. Figure 7 shows the comparison between the experimental radiative heat fluxes, indicated by continuous lines, and the simulated ones, indicated by dashed lines. The numeration of the sensors denotes the distance from the jet axis. During the first 10 seconds and except for sensor 1, simulation misrepresents the experimental radiative heat flux dynamics, resulting in significant underestimation. The dissimilarity may be attributed to both physical and numerical factors. First of all, the sudden release and combustion of the high pressure hydrogen may cause the movement and entrainment of dust or other particles present on the gallery ground, which would affect the emitting volume and radiation intensity. Secondly, the exact location of the niche where the sensors are placed is not known. Position of the niche walls with respect to the jet affects exposure of sensors to the entire flame length with consequences on the detected radiative heat flux, especially for sensors 3 and 4. Furthermore, experimental observations on ignition of high pressure gas releases shown a spherical broadening of the jet fire head during the first stage of the release $(0-400 \mathrm{~ms})$. The spherical zone was characterized by intense radiation in studies [23]-[24]. This dynamics and flame stages were not detected in simulation. Conversely, the simulated ignited release immediately stabilised into a jet fire. The reason may be due to either the time step not sufficiently low to correctly resolve the flame propagation, or the use of pressure-based incompressible solver. The need of a fine mesh to represent correctly the release source, the choice of time step to limit the required computational time and high speed of the release resulted in high CFL number (over 100). This may affect the predictive capability of simulation during the initial instants of the jet fire. The total mass imbalance was monitored during the simulation and resulted to be less than $0.5 \%$ at $36 \mathrm{~s}$ (end of the simulation). However, it is believed that the hydrogen mass balance shall be examined to have a precise idea of the simulation quality; this analysis could not be conducted because of absence of all the required data. Albeit the radiative heat flux discrepancies during the first phase of the release (about $10 \mathrm{~s}$ ), the second phase shown a better agreement between the experimental and simulated thermal radiation fluxes. Further remarks should be reported on the resolution of the computational mesh. As discussed in section 3.3, the grid was designed heeding the grid refinement where higher gradients and complexity of the flow are expected, according to the available best practices and numerical requirements formulated for this class of problems. Possible numerical diffusion was addressed using second order upwind scheme. However, it would be beneficial to further extend the analysis with a grid sensitivity study, to ensure the grid independency.

The simulated flame length was calculated as the region of the flame characterised by range of temperature 1300-1500 K, according to the experimental observations on visible flame length made in [25]. The resulting distance is represented by red bars in Figure 8, where simulations are compared to the experimental measurements made through a video camera. Flame length is well reproduced for a wide range of pressure decay in the tank, whereas it is over-predicted during the final phase of the release ( $p<200$ bar). This final trend can be attributed to the analogous mass flow rate overestimation (Figure 5). However, a sort of discontinuity in the experimental flame length trend around 100 bar should be noted, which may be due to measurements inaccuracy.

The sensitivity of simulation results to variation of turbulent flow characteristics at the release source was analysed. It was found that the change of turbulence intensity (TI) and turbulent length scale (TLS) from $\mathrm{TI}=30 \%$ and $\mathrm{TLS}=0.33 \mathrm{D}_{\text {eff }}$ to $\mathrm{TI}=4 \%$ and $\mathrm{TLS}=0.07 \mathrm{D}_{\text {eff }}$ has a considerable effect (up to $30 \%$ decrease) on the monitored radiative heat flux in the closest sensors at distances 1.0-1.5 m. The set of turbulence characteristics were defined according to a parametric study conducted at HySAFER on hydrogen concentration jet decay $\left(\mathrm{TI}=30 \%, \mathrm{TLS}=0.33 \mathrm{D}_{\text {eff }}\right)$ and experimental data on air under-expanded jets $\left(\mathrm{TI}=4 \%\right.$ and $\left.\mathrm{TLS}=0.07 \mathrm{D}_{\text {eff }}\right)[26]$. Minor effect of turbulent characteristics on radiative heat flux was found by the authors for steady state cryogenic jet fires where maximum variation was $15 \%$ [27]. This difference is presumed to be due to the different source modelling technique, as the volumetric source is more sensitive to the applied turbulence characteristics whereas they have minor effect for the constant diameter notional nozzle implementation with specified velocity at inflow boundary condition. The water vapour in air was found to have a greater effect on the thermal radiation absorbed in the surroundings of the flame. The effect was seen to be larger with the increase of distance from the flame. 


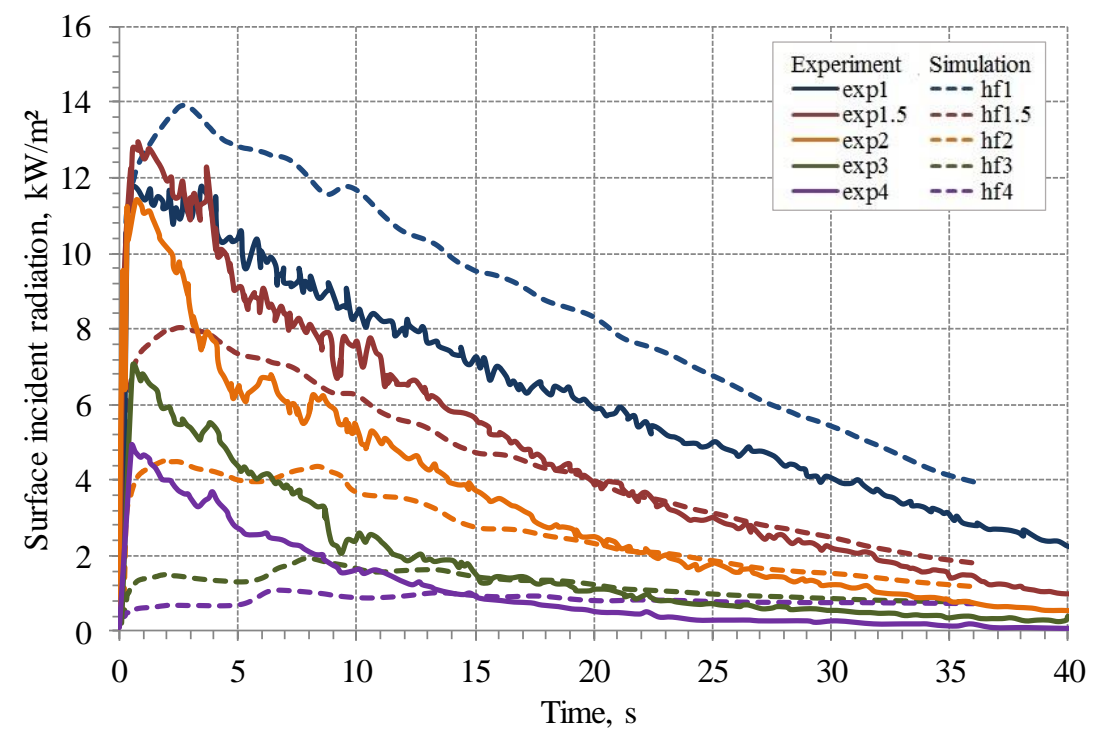

Figure 7. Radiative heat flux: simulation versus experiment

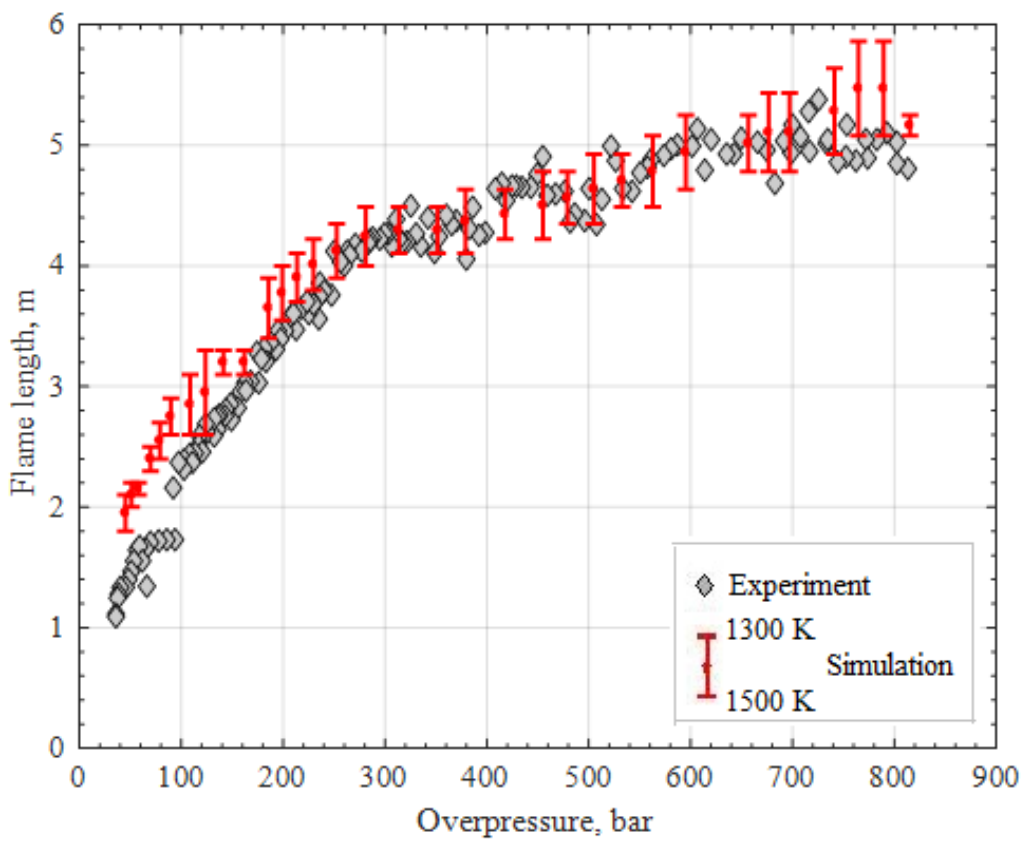

Figure 8. Flame length: simulation versus experiment

\section{CONCLUSIONS}

The thermal hazards from a high pressure (900 bar) hydrogen jet fire have been investigated numerically. Realizable k- $\varepsilon$ turbulence model was applied along with Eddy Dissipation Concept for combustion and DO model for radiation simulations. The blowdown from a high-pressure hydrogen storage tank was modelled as first adiabatic and then isothermal process to account heat transfer with environment, and the mass flow rate was evaluated using discharge coefficient $C_{d}$ equal to 0.7. The transient release was modelled via the volumetric source implementation of the notional nozzle. Simulation results show excellent CFD model capability to predict flame dynamics with pressure decrease for a large part of the blowdown process with slight overestimation for lower tank overpressures. In spite of close agreement between the experimental and simulated flame lengths, modelling of radiative heat flux had a twofold 
limited predictive capability during the first stage of hydrogen release $(t=0-10 \mathrm{~s})$ and quite a good agreement at later stage ( $t=10-35 \mathrm{~s}$ ). This may suggest that the experimental radiation was affected by some physical processes not unaccounted in CFD model, e.g. entrainment in jet flame and radiation of dust. However, the first stage of the release results to be the most dangerous, as it is characterized by the highest thermal radiation and flame length. It is therefore of primary importance to perform further numerical investigations to obtain better reproduction of experiment.

\section{ACKNOWLEDGEMENTS}

This study has received funding from EPSRC SUPERGEN H2FC Hub project (EP/J016454/1) and the Fuel Cell and Hydrogen 2 Joint Undertaking under grant agreement No.736648 (NET-Tools project). This Joint Undertaking received support from the European Union's Horizon 2020 research and innovation programme, and Hydrogen Europe and N.ERGHY.

\section{REFERENCES}

[1] S. L. Brennan, D. V. Makarov, and V. Molkov, "LES of high pressure hydrogen jet fire," J. Loss Prev. Process Ind., vol. 22, no. 3, pp. 353-359, 2009.

[2] W. G. Houf, G. H. Evans, and R. W. Schefer, "Analysis of jet flames and unignited jets from unintended releases of hydrogen," Int. J. Hydrogen Energy, vol. 34, no. 14, pp. 5961-5969, 2009.

[3] J. Zheng, H. Bie, P. Xu, P. Liu,Y. Zhao, H. Chen, X. Liu, L. Zhao, "Numerical simulation of high-pressure hydrogen jet flames during bonfire test," Int. J. Hydrogen Energy, vol. 37, no. 1, pp. 783-790, 2012.

[4] C. J. Wang, J. X. Wen, Z. B. Chen, and S. Dembele, "Predicting radiative characteristics of hydrogen and hydrogen/methane jet fires using FireFOAM," Int. J. Hydrogen Energy, vol. 39, no. 35, pp. 20560-20569, 2014.

[5] C. Proust, D. Jamois, and E. Studer, "High pressure hydrogen fires," Int. J. Hydrogen Energy, vol. 36, no. 3, pp. 2367-2373, 2011.

[6] C. Proust, "Personal communication", 2016 INERIS.

[7] E. Studer, "Personal communication", 2016 CEA.

[8] T. H. Shih, W. W. Liou, A. Shabbir, Z. Yang, J. Zhu, "A new eddy-viscosity model for high Reynolds number turbulent flows - model development and validation," Comput. Fluids, vol. 24, no. 3, pp. 227-238, 1995.

[9] ANSYS Fluent, Theory Guide, 2016.

[10] B. Magnussen, "On the structure of turbulence and a generalized eddy dissipation concept for chemical reaction in turbulent flow," Am. Inst. Aeronaut. Astronaut., 1981.

[11] V. Molkov, V. Shentsov, S. Brennan, and D. Makarov, "Hydrogen non-premixed combustion in enclosure with one vent and sustained release: Numerical experiments," Int. J. Hydrogen Energy, vol. 39, no. 20, pp. 10788-10801, 2014.

[12] N. Peters, B. Rogg, Reduced kinetic mechanisms for applications in combustion systems, Berlin; Ne. 1993.

[13] J. Y. Murthy and S. R. Mathur, "A finite volume method for radiative heat transfer using unstructured meshes," J. Quant. Spectrosc. Radiat. Transf., vol. 12, no. 12, pp. 313-321, 1998. 
[14] V. Molkov, Fundamentals of Hydrogen Safety Engineering I, 2012.

[15] R. W. Schefer, W. G. Houf, T. C. Williams, B. Bourne, and J. Colton, "Characterization of highpressure, underexpanded hydrogen-jet flames," Int. J. Hydrogen Energy, vol. 32, no. 12, pp. 2081-2093, 2007.

[16] V. Molkov, V. Makarov, and M. V. Bragin, "Physics and modelling of underexpanded jets and hydrogen dispersion in atmosphere," Phys. Extrem. States Matter, pp. 146-149, 2009.

[17] V. Molkov and V. Shentsov, "Numerical and physical requirements to simulation of gas release and dispersion in an enclosure with one vent," Int. J. Hydrogen Energy, vol. 39, no. 25, pp. 13328-13345, 2014.

[18] D. V. Reddy, K. Sobhan, L. Liu, and J. D. Young, "Size effect on fire resistance of structural concrete," Eng. Struct., vol. 99, pp. 468-478, 2015.

[19] Mikron istrument company Inc., "Table of emissivity for various surfaces". [Online]. Available at: www-eng.lbl.gov [accessed 15.02.17]

[20] NASA, "Earth fact sheet". [Online]. Available at:

https://nssdc.gsfc.nasa.gov/planetary/factsheet/earthfact.html [accessed 15.02.17]

[21] C. Hubbard, G. L.; Tien, "Infrared Mean Absorption Coefficients of Luminous Flames and Smoke," J. Heat Transfer, vol. 100, pp. 235-239, 1978.

[22] ANSYS Fluent, “User's Guide,” 2016.

[23] A. Kessler, A. Schreiber,C. Wassmer, L. Deimling, S. Knapp, V. Weiser, K. Sachsenheimer, G. Langer, N. Eisenreich, "Ignition of hydrogen jet fires from high pressure storage," Int. J. Hydrogen Energy, vol. 39, no. 35, pp. 20554-20559, 2014.

[24] E. Studer, D. Jamois, S. Jallais, G. Leroy, J. Hebrard, and V. Blanchetière, "Properties of largescale methane/hydrogen jet fires," Int. J. Hydrogen Energy, vol. 34, no. 23, pp. 9611-9619, 2009.

[25] R. Schefer, B. Houf, B. Bourne, and J. Colton, "Experimental Measurements to Characterize the Thermal and Radiation Properties of an Open-flame Hydrogen Plume," in In Proceedings of the 15th annual hydrogen conference and hydrogen expo, 2004.

[26] S. G. Chuech, M.-C. Lai, and G. M. Faeth, "Structure of turbulent sonic underexpanded free jets," AIAA J., vol. 27, no. 5, pp. 549-559, 1989.

[27] D. Cirrone, D. Makarov, and V. Molkov, "Thermal radiation from cryogenic hydrogen jet fires", International Conference on Hydrogen Safety, Hamburg, Germany, 2017 